\title{
Application of Nursing Intervention Guided by King's Interactive Standard Theory in Patients with Lumbar Disc Herniation Undergoing Conservative Treatment
}

\author{
W. J. FU AND L. H. YING*
}

Department of Spine Surgery, The First People's Hospital of Wenling, Wenling 317500, China

Fu et al.: Lumbar Disc Herniation Undergoing Conservative Treatment

To explore the application effect of nursing intervention guided by King's interactive standard theory in patients with lumbar disc herniation undergoing conservative treatment. Total of 136 patients with lumbar disc herniation admitted to our hospital from June 2019 to May 2020 were randomly divided into interactive nursing group and routine nursing group. The interactive nursing group was given nursing intervention guided by King's interactive standard theory and the routine nursing group was given routine nursing guidance. The disease cognition rate, incidence of adverse behavior, lumbar function and pain degree were compared between the two groups. The disease cognition rates of main symptoms, disease type, familiarity with conservative treatment, necessity of hard bed rest, feasible surgical treatment in severe cases and causes of disease in interactive nursing group were higher than those in routine nursing group ( $<\mathbf{0 . 0 5}$ ); the incidences of standing or sitting for a long time, smoking or bad eating habits, rest on a soft bed, carrying heavy objects, poor compliance and other adverse behaviors in the interactive nursing group were lower than those in the routine nursing group $(p<0.05)$; the range of flexion motion, lateral flexion motion and rotation motion of the interactive nursing group was higher than that of the routine nursing group ( $\mathbf{p}<\mathbf{0 . 0 5}$ ); after nursing, the visual analogue scale score of the interactive nursing group was lower than that of the routine nursing group $(p<0.05)$. The nursing intervention guided by King's interactive standard theory could improve the disease cognition rate of patients with lumbar disc herniation conservative treatment, reduce their bad acts, improve their lumbar function and relieve their pain.

Key words: King's interactive standard theory, lumbar disc herniation, bad act, lumbar function

Lumbar disc herniation (LDH) is a common orthopedic disease. It is prone to recurrent attacks, seriously affects patient's life and work and causes anxiety, depression and other adverse emotions. Most LDH patients can recover their working ability and improve their living quality through conservative treatment. Studies have shown that bed rest and back muscle exercise can effectively relieve pain, but overwork will cause repeated attacks of $\mathrm{LDH}^{[1]}$. $\mathrm{LDH}$ patients are mostly middle-aged and elderly people. Clinical investigation shows that patients have low cognition of diseases, with lack of social support and poor compliance of rehabilitation exercise during conservative treatment ${ }^{[2]}$. King's interactive compliance theory focuses on interpersonal interaction, describing the correct cognition of nurses and patients on themselves, their roles and development. It holds that, nurse-patient relationship is the interactional relationship of personal system, interpersonal system and social system. In the process of nursing, it is necessary to improve patient's self-cognition of diseases and communication between nurses and patients ${ }^{[3,4]}$. King's interactive compliance theory emphasizes patient's participation in nursing process and attaches importance to the positive role of nurse-patient interaction. In this study, based on King's interactive compliance theory, nursing intervention was given to patients with LDH undergoing conservative treatment, as reported below. 


\section{MATERIALS AND METHODS}

\section{Research object:}

$136 \mathrm{LDH}$ patients admitted to our hospital from June 2019 to May 2020 were randomly divided into interactive nursing group and routine nursing group. The interactive nursing group was given nursing intervention guided by King's interactive compliance theory, while the routine nursing group was given routine nursing guidance. There were 68 cases in interactive nursing group, with 30 male cases and 29 female cases. They were aged 29-67 y, with an average age of $(43.06 \pm 6.83) \mathrm{y}$; education level: 26 cases of junior high school and below, 28 cases of high school/technical secondary school, 14 cases of junior college and above; their course of disease ranged from 1 to $7 \mathrm{y}$, with an average of $(3.17 \pm 0.86)$ y. There were 68 cases in routine nursing group, with 42 male cases and 26 female cases. They were aged 31-69 y, with an average age of $(43.816 \pm 6.95) \mathrm{y}$; education level: 30 cases of junior high school and below, 25 cases of high school/technical secondary school, 13 cases of junior college and above; their course of disease ranged from 10 mo to $6 \mathrm{y}$ with an average of $(3.39 \pm 1.03) \mathrm{y}$. There was no significant difference in general data between the two groups $(\mathrm{p}>0.05)$.

\section{Inclusion and exclusion criteria:}

Inclusion criteria-Typical symptoms and signs of $\mathrm{LDH}$, straight leg elevation test $<60^{\circ}$, obvious lower limb symptoms, first attack; receiving conservative treatment voluntarily; no disturbance of consciousness and able to read and write; voluntarily participating in the study and signing the consent form.

Exclusion criteria-History of mental illness or cognitive dysfunction; women during pregnancy or lactation; complicated with malignant tumor.

\section{Methods:}

Conservative treatment: In acute edema stage, mannitol, dexamethasone and other drugs were used for dehydration treatment for $5 \mathrm{~d}$ and neurotrophic drugs were given for $14 \mathrm{~d}$. Three-dimensional traction bed (produced by Jinan Huafei Industry Co., Ltd.) was used for traction treatment. Patients aged less than 65 y received traction treatment once a week, with 30 min each time, four times during the course of treatment. Patients aged over $65 \mathrm{y}$ received traction treatment twice a week, with 10-20 min each time, eight times in a course of treatment. Rolling and kneading methods were used in massage, from light to heavy and from slow to fast. Appropriate pulling and stretching were used twice a week, with $21 \mathrm{~d}$ as a course of treatment.

Routine nursing group: Routine nursing was given, including: health knowledge education: explaining the functions and effects of drug therapy, traction therapy and massage to patients, instructing patients in acute stage to stay in bed, gradually carry out activities after pain relief and avoid excessive activities; instructing patients to take reasonable diet during treatment. Lumbar functional exercise: mainly including forward flexion and backward extension, left-right rotation, flying-bird-type movement of lumbar back muscles and slow backward walk with support. Each action was repeated for 5-20 times and each exercise lasted for $20 \mathrm{~min}$. Correct posture training: nurses instructed patients to take laborsaving actions, such as correct lying, standing and sitting postures. The exercise was taken once a day, with 30 min each time.

Interactive nursing group: Establishment of an interactive compliance group; the group consisted of attending doctors, rehabilitation therapists, psychological counselors and nurses, who had worked for more than $3 \mathrm{y}$ and received training on King's interactive compliance theory. Establishment of perceptual interaction; when nurses and patients came into contact for the first time, the nurses interacted with patients in time, evaluated the patients educational level, disease cognition level and acceptance ability and established mutual trust with patients; the nurses collected patients data and evaluated their needs; at the same time, the nurses made self-introduction in detail to deepen mutual understanding, enhance mutual trust and form good perception and judgment, thus laying an emotional foundation for follow-up nursing. Establishment of a unified system: multi-form communication was carried out according to the characteristics of patient's personality, educational level and family support. For those with higher educational level, the nursing knowledge manuals of LDH were distributed and propaganda and education were carried out in combination with video. For those with lower educational level, the nurses focused on explaining the contents of the manual repeatedly, with the aim of reaching a consensus on the importance and necessity of $\mathrm{LDH}$ rehabilitation exercise and establishing 
specific rehabilitation training objectives; after that, nurses, patients and their family members discussed together to formulate rehabilitation training plan. Nurses mainly gave guidance and explanation, while family members cooperated, supplemented and persuaded. Patients made their own decisions and asked questions. The three parties jointly established the methods and projects of rehabilitation training objectives, forming a unified system of restriction and interaction. Implementation and evaluation: before rehabilitation training, nurses designed the training contents into a form and patients carried on training according to the form content. Nurses and the patient's family members supervised the training and evaluated the effect in time; nurses mainly played the role of assistance, helping patients to act skillfully and encouraging them to complete each action diligently. Establishment of social support system and continuous interactive system: nurses invited patients with high enthusiasm and good effect of rehabilitation training to share their own experiences in rehabilitation training, thus encouraging other patients to actively participate and enhancing their confidence in rehabilitation; nurses also urged the patient's family members to give encouragement and care to patients; before discharge, nurses created WeChat group of patients and asked them to leave their telephone numbers and emails. After discharge, the responsible nurses got to know the patients through WeChat group, email and telephone, understood the progress and effect of their rehabilitation training and answered patients questions to realize interaction and feedback in time. Both groups received continuous nursing for 3 mo.

\section{Observation indicators:}

Disease cognition rate: After 3 mo of continuous nursing, the self-made questionnaire on diseaserelated knowledge was used to evaluate the disease cognition rates of the two groups, including the main symptoms of the disease, the type of the disease, familiarity with conservative treatment, the necessity of rest on a hard bed, feasible surgical treatment in severe cases and factors inducing the disease, etc.

Incidence of bad acts: After 3 mo of continuous nursing, the self-made questionnaire on bad acts was used to evaluate the incidence of bad acts in two groups, including standing or sitting for a long time, smoking or bad eating habits, rest on a soft bed, carrying heavy objects, poor compliance, etc.
Lumbar function: The lumbar function of patients was evaluated, including the range of flexion motion, lateral flexion motion and rotation motion. The evaluation was carried out after the first treatment and after continuous nursing for 3 mo.

Pain degree: Visual analogue scale (VAS) was used before and after nursing. The score ranges from 0 to 10 points. The higher the score is, the more severe the pain. The evaluation was carried out after the first treatment and after continuous nursing for 3 mo.

\section{Statistical processing:}

The counting data is expressed in percentage (\%) and the $\chi^{2}$ test or Fisher exact probability method is adopted. The measurement data was represented by $(\overline{\mathrm{x}} \pm \mathrm{s})$ and independent samples t-test or paired samples t-test was used, $\mathrm{p}<0.05$ indicated statistically significant difference. Statistical package for the social sciences (SPSS) 22.0 software was used for data processing.

\section{RESULTS AND DISCUSSION}

Comparison of disease cognition is done where the disease cognition rate of the interactive nursing group was higher than that of the routine nursing group $(\mathrm{p}<0.05)$ (Table 1).

Comparison of the incidence of bad acts is done where the incidence of bad acts in interactive nursing group was lower than that in routine nursing group $(\mathrm{p}<0.05)$ (Table 2).

Comparison of lumbar function between two groups is done where there was no significant difference in the range of flexion motion, lateral flexion motion and rotation motion between the two groups before nursing $(p>0.05)$. After nursing, the ranges of motion of flexion, lateral flexion and rotation of the two groups increased than those before nursing and the range of flexion motion, lateral flexion motion and rotation motion of the interactive nursing group was significantly larger than that of the routine nursing group $(\mathrm{p}<0.05)$ (Table 3$)$.

Comparison of pain degree is done where there was no significant difference in VAS score between the two groups before nursing ( $>0.05)$. After nursing, the VAS score of the interactive nursing group was lower than that of the routine nursing group $(\mathrm{p}<0.05)$ 
TABLE 1: COMPARISON OF DISEASE COGNITION RATE BETWEEN TWO GROUPS CASE (\%)

\begin{tabular}{|c|c|c|c|c|c|c|c|c|}
\hline Group & $\begin{array}{l}\text { Main symptoms } \\
\text { of disease }\end{array}$ & \multicolumn{2}{|c|}{ Type of disease } & \multicolumn{2}{|c|}{$\begin{array}{c}\text { Familiar with } \\
\text { conservative } \\
\text { treatment }\end{array}$} & $\begin{array}{l}\text { Necessity of } \\
\text { rest on a hard } \\
\text { bed }\end{array}$ & $\begin{array}{c}\text { Feasible } \\
\text { surgical } \\
\text { treatment in } \\
\text { severe cases }\end{array}$ & $\begin{array}{l}\text { Factors } \\
\text { inducing } \\
\text { diseases }\end{array}$ \\
\hline $\begin{array}{l}\text { Interactive } \\
\text { nursing group } \\
(n=68)\end{array}$ & $63(92.65)$ & \multicolumn{2}{|c|}{$59(86.76)$} & \multicolumn{2}{|c|}{$61(89.71)$} & $58(85.29)$ & $57(83.82)$ & $55(80.88)$ \\
\hline $\begin{array}{l}\text { Routine nursing } \\
\text { group }(n=68)\end{array}$ & $34(50.00)$ & \multicolumn{2}{|c|}{$32(47.06)$} & \multicolumn{2}{|c|}{27 (39.71) } & $37(54.41)$ & 35 (51.47) & 39 (57.35) \\
\hline$\chi^{2}$ & 30.234 & \multicolumn{2}{|c|}{24.211} & \multicolumn{2}{|c|}{31.676} & 15.398 & 16.261 & 8.819 \\
\hline$\underline{p}$ & 0.000 & \multicolumn{2}{|c|}{0.000} & \multicolumn{2}{|c|}{0.000} & 0.000 & 0.000 & 0.003 \\
\hline Group & $\begin{array}{r}\text { Standing or si } \\
\text { for a long ti }\end{array}$ & $\begin{array}{l}\text { itting } \\
\text { me }\end{array}$ & $\begin{array}{r}\text { Smoking } \\
\text { eating } h\end{array}$ & $\begin{array}{l}\text { or bad } \\
\text { abits }\end{array}$ & Rest on & a soft bed & $\begin{array}{l}\text { rying heavy } \\
\text { objects }\end{array}$ & Poor compliance \\
\hline $\begin{array}{l}\text { Interactive nursing } \\
\text { group }(n=68)\end{array}$ & $33(48.53)$ & & $32(47$ & 06) & 31 & 45.59) & $26(38.24)$ & $23(33.82)$ \\
\hline $\begin{array}{l}\text { Routine nursing } \\
\text { group }(n=68)\end{array}$ & $52(76.47)$ & & $47(69$ & 12) & 50 & 73.53) & $45(66.18)$ & 48 (70.59) \\
\hline$\chi^{2}$ & 11.325 & & 6.79 & & & .020 & 10.637 & 18.418 \\
\hline $\mathrm{p}$ & 0.001 & & 0.00 & & & 001 & 0.001 & 0.000 \\
\hline
\end{tabular}

TABLE 3: COMPARISON OF LUMBAR FUNCTION BETWEEN TWO GROUPS $(\overline{\mathbf{x}} \pm \mathbf{s})$

\begin{tabular}{|c|c|c|c|c|c|c|}
\hline \multirow{2}{*}{ Group } & \multicolumn{2}{|c|}{ Range of flexion motion } & \multicolumn{2}{|c|}{ Range of lateral flexion motion } & \multicolumn{2}{|c|}{ Range of rotation motion } \\
\hline & Before nursing & After nursing & Before nursing & After nursing & Before nursing & After nursing \\
\hline $\begin{array}{l}\text { Interactive } \\
\text { nursing group } \\
(n=68)\end{array}$ & $53.46 \pm 7.58$ & $69.52 \pm 8.17$ & $39.61 \pm 10.89$ & $51.72 \pm 8.04$ & $39.55 \pm 11.03$ & $48.65 \pm 7.33$ \\
\hline $\begin{array}{l}\text { Routine nursing } \\
\text { group }(n=68)\end{array}$ & $54.01 \pm 8.45$ & $63.70 \pm 9.21$ & $40.32 \pm 9.95$ & $44.83 \pm 7.56$ & $38.14 \pm 10.29$ & $43.70 \pm 8.68$ \\
\hline $\mathrm{t}$ & 0.400 & 3.898 & 0.397 & 5.148 & 0.771 & 18.182 \\
\hline $\mathrm{p}$ & 0.690 & 0.000 & 0.692 & 0.000 & 0.442 & 0.000 \\
\hline
\end{tabular}

TABLE 4: COMPARISON OF PAIN DEGREE BETWEEN TWO GROUPS ( $\overline{\mathbf{x}} \pm \mathbf{s}$, POINT)

\begin{tabular}{lcccc}
\hline Group & Before nursing & After nursing & $\mathrm{t}$ & $\mathrm{p}$ \\
\hline $\begin{array}{l}\text { Interactive nursing } \\
\text { group ( } \mathrm{n}=68)\end{array}$ & $6.73 \pm 1.48$ & $2.82 \pm 0.45$ & 20.843 & 0.000 \\
$\begin{array}{l}\text { Routine nursing group } \\
(\mathrm{n}=68)\end{array}$ & $6.50 \pm 1.34$ & $3.66 \pm 1.57$ & 11.346 & 0.000 \\
$\mathrm{t}$ & 0.937 & 4.241 & & \\
$\mathrm{p}$ & 0.350 & 0.000 & & \\
\hline
\end{tabular}

(Table 4).

The incidence of LDH is related to many factors, such as age, occupation, heredity, smoking, etc. In recent years, the incidence of $\mathrm{LDH}$ is on the rise due to the increasing pressure of life. Conservative treatment is the first choice for LDH treatment. Because of the differences in patient's educational level and understanding ability, the compliance of rehabilitation training is poor during conservative treatment and the bad act habits and lifestyle have not been changed, which affects the treatment effect $^{[5]}$. Therefore, effective nursing intervention during conservative treatment of LDH has important clinical significance. King's interactive compliance theory includes social system, interpersonal system and personal system. It emphasizes effective communication between nurses and patients and 
promotes mutual influence and correct perception, thus gradually completes nursing goals ${ }^{[6]}$. Research shows that King's interactive compliance theory improves nurse-patient communication effect and promotes patients subjective initiative to improve nursing quality ${ }^{[7]}$.

In this study, the nursing intervention guided by King's interactive compliance theory was applied to LDH conservative treatment. The results showed that the disease cognition rate of the interactive nursing group was higher than that of the routine nursing group, indicating that nursing intervention guided by King's interactive compliance theory could improve the disease cognition rate of LDH patients. Nursing intervention guided by King's interactive compliance theory promoted communication between nurses and patients by implementing planned and purposeful intervention for patients in combination with action demonstration and videos, thus improving patients understanding of LDH symptoms, conservative treatment methods, curative effect and inducing factors. At the same time, the patient's family members were also taken as education objects, which improved patient's initiative and enthusiasm in learning together. In addition, family members, as family supporters of patients, were conducive to cultivating a good family atmosphere. Their participation was beneficial to formulating mutually recognized behavioral intervention plans for patients rehabilitation training, reducing family unfavorable factors and ensuring the maintenance of patients enthusiasm in treatment ${ }^{[8,9]}$. Multi-interaction between nurses and patients, family members and patients, family members and nurses helped to consolidate and strengthen the interaction, increase the breadth and depth of communication, further enhance the understanding of patients and their families on diseases and treatment methods and eliminate difficulties in time. Communication between patients and their family member was helpful to strengthen patient's cognition of unfamiliar knowledge points, timely correct measures cognition and consolidate $\operatorname{cognition}^{[10]}$.

The results of this study showed that the incidence of bad acts in the interactive nursing group was lower than that in the routine nursing group and the range of flexion motion, lateral flexion motion and rotation motion of the interactive nursing group was higher than that of the routine nursing group, indicating that nursing intervention guided by King's interactive compliance theory was helpful to reduce the bad acts of LDH patients and promote the recovery of lumbar function. In this study, patients were guided to carry out body position training and change bad living habits. The patients were also guided to protect lumbar vertebrae in labor and work. Avoidance of heavy objects lifting and family member's participation was emphasized ${ }^{[11]}$. All these would help patients develop correct standing, sitting and behavior habits ${ }^{[12]}$. WeChat and E-mail are daily communication tools for the public and their beneficial value in health education has been clinically confirmed ${ }^{[13]}$. Fronczek research also shows that King's interactive compliance theory is helpful to improve the effect of distance education ${ }^{[14]}$. This study provided an online communication platform for communication among patients and communication between nurses and patients by establishing WeChat group, thus shortening the distance between patients and nurses and helping nurses to play a coordinating role to ensure more effective clinical nursing. Relevant research shows that the scenario interactive intervention model created by King's interactive compliance theory can effectively promote the cognitive interaction between nurses and patients, promote the harmonious relationship between nurses and patients and help to improve patients' cognition level of theoretical knowledge ${ }^{[15]}$. According to the results of this study, the VAS score of the study group was lower than that of the control group, indicating that nursing intervention guided by King's interactive compliance theory could obviously relieve the pain of patients. It may be because of the inflammatory reaction in the body has been improved by effective improvement of lumbar function ${ }^{[16]}$.

To sum up, nursing intervention guided by King's interactive compliance theory could improve disease cognition rate, reduce bad acts, improve lumbar function and relieve pain, with certain clinical promotion value.

\section{Conflicts of interest:}

The authors declared no conflict of interest.

\section{REFERENCES}

1. Li GP, Wang CL, Yin F. Effect of rapid rehabilitation surgical nursing on postoperative complications, limb function and self-efficacy of patients with lumbar disc herniation. China Med Her 2018;15(14):147-51. 
2. Liu MR, Wang QL, Zhao W. Therapeutic effects of rehabilitation nursing intervention on intervertebral disc herniation. Hebei Med J 2018;40(1):157-9.

3. De Leon-Demare K, MacDonald J, Gregory DM, Katz A, Halas G. Articulating nurse practitioner practice using King's theory of goal attainment. J Am Assoc Nurse Pract 2015;27(11):6316.

4. Gao B, Xie J. Influence of nursing mode based on King's interactive compliance theory on living quality and compliance of hemodialysis patients. J Bengbu Med Coll 2018;43(6):1226.

5. Zarei B, Valiee S, Nouri B, Khosravi F, Fathi M. The effect of multimedia-based nursing visit on preoperative anxiety and vital signs in patients undergoing lumbar disc herniation surgery: A randomised clinical trial. J Perioper Pract 2018;28:715.

6. Zheng XY, Wang P. Calling for the impact of the interactive compliance model on the self-management efficacy and blood sugar control of gestational diabetes patients. J Clin Res 2018;35(3):615-7.

7. Araujo ES, Silva LD, Moreira TM, Almeida PC, Freitas MC, Guedes MV. Nursing care to patients with diabetes based on King's Theory. Rev Bras Enfermagem 2018;71(3):1092-8.

8. Fan XH. Influence of family members participating in nursing intervention on postoperative rehabilitation of patients with lumbar disc herniation. Nurs Pract Res 2016;13(24):149-1.

9. Deng Z, Tang XH, Tang TS. Observation on the effect of combined rehabilitation nursing in minimally invasive surgery for lumbar disc herniation. J Bengbu Med Coll 2018;43(1):1079.

10. Li GJ, Zhao H, Pang L. Application of King's up-to-thestandard theory to patients subjected to early neck-andshoulder rehab exercises after laryngeal cancer surgery. J Nurs Sci 2018;33(8),64-5.
11. Wang K, Dai J, Liu T, Wang Q, Pang Y. LncRNA ZEB2-AS1 regulates the drug resistance of acute myeloid leukemia via the miR-142-3p/INPP4B axis. RSC Adv 2019;9(67):39495-504.

12. Zhu YH, Wu LF. Application effect of psychological nursing intervention based on king compliance theory in patients with benign prostatic hyperplasia after operation. Chin J Control Endemic Dis 2017;32(9):1044-5.

13. Yuxia HE, Huagang LI. Application of WeChat health education platform in the continuous nursing of patients with chronic renal failure. J Clin Med Pract 2019;23(19):107-11.

14. Fronczek AE, Rouhana NA. Attaining mutual goals in telehealth encounters: Utilizing King's framework for telenursing practice. Nurs Sci Q 2018;31(3):233-6.

15. Zheng YL, Wang HL, Wang HL. The role of interactive compliance theory in psychological care of patients with lumbar disc herniation. Chin Foreign Med Res 2019;17(26):52-3.

16. Li L. Analysis of clinical efficacy of comfort nursing on patients with lumbar disc herniation. Shanxi Med J 2018;47(10):11921.

This is an open access article distributed under the terms of the Creative Commons Attribution-NonCommercial-ShareAlike 3.0 License, which allows others to remix, tweak, and build upon the work non-commercially, as long as the author is credited and the new creations are licensed under the identical terms

This article was originally published in a special issue,

"Therapeutic Perspectives in Biomedical Research and Pharmaceutical Sciences and their Nursing Methods"

Indian J Pharm Sci 2021:83(4)Spl issue “184-189" 